\title{
O uso do computador como estratégia para discutir em sala de aula o tabagismo na adolescência
}

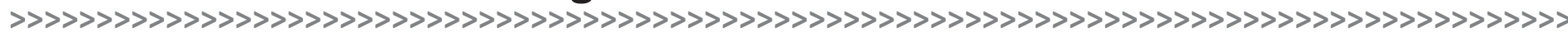

\author{
Luciana Maria de Jesus Baptista Gomes*
}

\section{Resumo:}

Este artigo descreve um relato de experiência desenvolvido em uma escola da área suburbana da cidade do Rio de Janeiro, com duas turmas de 9o ano do Ensino Fundamental. Reconhecendo a necessidade de discutir o tabagismo na adolescência, haja vista que este público é considerado "reserva de reabastecimento" pelas indústrias do tabaco ao mesmo tempo em que o tabagismo é a principal causa de morte evitável pela Organização Mundial de Saúde (WHO, 2013), a estratégia foi a de utilizar o computador como uma ferramenta didática, a qual os alunos puderam utilizar em diferentes momentos. Foi aplicado inicialmente um questionário para diagnose das turmas e os resultados das atividades foram analisados à luz de Vygotsky. Apesar de o tabagismo ser um tema conhecido pelos alunos, o uso do computador foi motivador para que eles se sentissem estimulados a participar, levando a um engajamento cada vez maior a cada etapa do projeto.

\section{Palavras-chave:}

Adolescência. Computador. Tabagismo. Vygotsky.

\begin{abstract}
:
This article describes an experience report developed in a school in the suburban area of the city of Rio de Janeiro, with two groups of 9th grade of elementary school. Recognizing the need to address smoking in adolescence, given the fact that the public is considered "reserve replenishment" by the tobacco industry while cigarette smoking is the leading preventable cause of death by the World Health Organization (WHO), the strategy was to use the computer as a teaching tool, in which the students could use it at different times. It was initially a questionnaire for the diagnosis of classes and the results of the activities were analyzed on the light of Vygotsky. Although smoking is a known issue for students, but computer use was motivating for them to feel encouraged to participate, leading to an increasing engagement in each stage of the project.
\end{abstract}

\section{Keywords:}

Adolescence. Computer. Smoking. Vygotsky.

* > Mestre em Ensino de Ciências (IFRJ). Professora de Biologia e de Ciências das redes estadual e municipal do Rio de Janeiro. E-mail: lucianajbg@yahoo.com.br. 


\section{Introdução}

A adolescência é uma etapa da vida que compreende a transição entre a infância e a vida adulta com um turbilhão de transformações biológicas que são inerentes à puberdade e que abrange reflexões sobre a maneira de se ver, de ver o outro e de se posicionar no mundo. Como pontuam Farina, Pereira e Argimon (2008, p. 1), a adolescência é uma “[...] etapa carregada de riscos ao desenvolvimento saudável, pois propicia padrões de comportamento arriscados".

Nesta mesma perspectiva, para Davim et al. (2009, p. 133),

[...] a adolescência é marcada por mudanças psicoafetivas e de conduta, constituindo um dos grupos mais sensíveis aos graves problemas na atualidade como fome, miséria, desnutrição, analfabetismo, prostituição, violência, abandono, desintegração familiar, independência quanto aos horários e locais para realizarem suas refeições.

Essa fase apresenta a rebeldia e o questionamento dos valores dos adultos como marcas e, aproveitando essa necessidade de se afirmar como indivíduo, a propaganda das indústrias interessadas nesse público tenta reforçar essas características em seus produtos. Dentre estas empresas, há as indústrias transnacionais do tabaco que consideram as crianças e os adolescentes como "reservas de reabastecimento" (BRASIL, 2002, p. 1), pois, uma vez dependentes, garantem mercado consumidor por longo tempo.

As empresas fumígenas ignoram o fato do tabagismo - hábito de fumar cigarro de tabaco - provocar uma doença identificada pela Classificação Internacional de Doença, CID, (BRASIL, 2008) como a síndrome da dependência. Essa doença é basicamente definida por um conjunto de sintomas desagradáveis que a pessoa sente ao se abster de determinada droga, como a nicotina, composto que provoca a efetiva dependência do cigarro.

Se por um lado os adolescentes são tratados como alvos estratégicos para as indústrias produtoras de cigarro de tabaco, por outro lado, a Organização Mundial de Saúde (OMS) considera o tabagismo como principal causa de morte evitável em todo mundo (WHO, 2013, p. 12).

Essa organização internacional aponta que o tabaco "[...] mata cerca de 6 milhões pessoas e causa mais de meio trilhão de dólares de dano econômico a cada ano. O tabaco vai matar 1 bilhão de pessoas neste século" (idem, 2013, p. 12). Se continuar a tendência de expansão do consumo do cigarro, ainda pela OMS, por volta de 2030, 5 milhões de pessoas em idade produtiva - entre 35 e 69 anos - morrerão anualmente em consequência do uso do tabaco. Podemos concluir, então, por um cálculo simples, que um adolescente de hoje, com idade entre 12 e 18 anos, pode ser uma vítima fatal dentre as mencionadas acima.

No Brasil, 27,2\% dos adolescentes do Ensino Fundamental e do Ensino Médio da rede pública de ensino já usaram tabaco uma vez na vida, com o primeiro uso ocorrendo por volta dos 12,8 anos (CEBRID, 2004, p. 326). Para tratar desse problema de saúde pública, a legislação brasileira, representada pela lei no 11343, de 23 de agosto de 2006 (BRASIL, 2006), ressalta a adoção de medidas educativas, trabalhando na direção da prevenção dos riscos causados pelo consumo de drogas, inclusive o tabagismo.

Diante desse quadro, a escola, reconhecida como lócus do ensino e enquanto instituição promotora de conhecimento e de valores, deve fomentar ações que levem o aluno adolescente a ponderar sobre os reais malefícios provocados pelo hábito de fumar.

Tendo em vista essas considerações, o presente trabalho é um relato de experiência que teve como objetivos: conhecer as concepções dos alunos sobre o tema Tabagismo e, a partir daqui, proporcionar momentos de discussão sobre o tabagismo na adolescência utilizando o computador como ferramenta didática. 


\section{Conhecendo o local de desenvolvimento das atividades e o público-alvo}

A escola onde as atividades ocorreram é da esfera municipal do Rio de Janeiro, em área urbana, a qual atende a alunos de comunidades não pacificadas. Essas comunidades apresentam episódios de violência - ao ponto da escola ser obrigada a fechar as portas por questão de segurança da comunidade escolar - e muitos alunos são cuidados pelos programas assistenciais governamentais, configurando uma escola que atende a classes média baixa e baixa.

Os alunos participantes, com idades entre 14 e 17 anos, compõem duas turmas de $9^{\circ}$ ano do Ensino Fundamental (EF) e demonstram interesse em estudar quando a aula envolve recursos midiáticos - como filmes e apresentações de assuntos de Ciências expostos em Power Point, por meio de projetor de imagem - e quando envolve o uso do computador. Os alunos possuem telefones celulares e os manejam sem dificuldades.

Como reconhecido em literatura acadêmica (Borba; Penteado, 2001, p. 46), os seres humanos desenvolvem técnicas e tecnologia para usufruírem de uma melhor qualidade de vida. Essas técnicas e tecnologia, por sua vez, modificam seu raciocínio, e esses mesmos seres humanos estão constantemente transformando essas técnicas. Assim, configura-se um ciclo: o de se criar tecnologia, ser alterado por ela, ao mesmo tempo em que esta mesma tecnologia é também modificada pela ação do ser humano.

Seguindo esta linha de raciocínio, por suas características apresentadas em sala de aula, os alunos desta pesquisa estão imersos em um mundo modificado pela tecnologia, sem receio para desfrutar de suas inúmeras possibilidades, as quais também modificam suas maneiras de se relacionarem com o mundo e com as demais pessoas.

\section{O percurso da pesquisa}

O projeto foi dividido em seis momentos pedagógicos realizados ao longo do ano letivo, que variavam em tempos-aula de cinquenta e cem minutos, dependendo da atividade proposta.

No primeiro dia do projeto, inicialmente, ocorreu uma conversa apresentando a proposta que faríamos ao longo do ano letivo, ou seja, a de que conversaríamos sobre alguns aspectos do tabagismo, como a definição da palavra, alguns motivos para as pessoas desenvolverem o tabagismo e o conhecimento de alguns fatores de riscos. Propositadamente, o projeto não recebeu nenhum nome, para que os alunos não se sentissem influenciados a concordar com a opinião da professora. Após essa introdução, foi aplicado um questionário com cinco perguntas (Apêndice 1) sobre o tema. O questionário teve como objetivo conhecer o perfil dos estudantes, no intuito de escolher uma melhor abordagem pedagógica para o assunto ao conhecer os alunos e sua realidade social.

As atividades seguintes foram realizadas em grupos pequenos de no máximo cinco alunos, escolhidos por eles mesmos. Esta foi uma estratégia adotada para desenvolver a postura dialógica entre os alunos e também em respeito às opiniões diferentes, além de estreitar laços de amizade (ZABALA, 1998, p. 123).

Aproveitando a matéria de Química e aludindo ao dia trinta e um de maio - Dia Mundial sem Tabaco -, foi distribuído a cada aluno um panfleto, conseguido num stand da campanha Rio: Cidade Livre do Tabaco, com uma imagem que apresentava as substâncias químicas presentes no cigarro, como formol, tolueno e naftalina. O objetivo da atividade foi de que os estudantes conhecessem as substâncias químicas e suas utilizações, que não são nada benéficas para o ser humano. Como uma forma de contextualizar a 
matéria, os alunos realizaram um exercício classificando as substâncias apresentadas em simples ou compostas.

A postura da professora de trazer para a sala de aula a discussão de um tema social - tabagismo na adolescência - aliado ao conteúdo curricular de Química corrobora com Milaré e Richetti (2008, p. 5) que defendem que

[...] o uso de temas no Ensino de Ciências e no Ensino de Química pode colaborar na concretização destes pontos em sala de aula, pois direcionam os conhecimentos científicos para uma finalidade prática, atribuindo importância para os alunos ao que é estudado e favorecendo a interdisciplinaridade. [...] Também colaboram com a discussão de aspectos sociais, políticos e econômicos, que são elementos não disciplinares que auxiliam na problematização e fazem parte da realidade dos alunos.

No terceiro encontro, aproveitando que os alunos são muito motivados para conhecer e utilizar os materiais midiáticos que usam a informática como tecnologia, os grupos foram para a Sala de Informática e escolheram uma imagem da internet que representava o que eles pensavam sobre o tabagismo. As imagens foram impressas (Figura 1 - fotografia 1a) e depois ocorreu a confecção de cartazes que foram expostos na escola.

Figura 1 - Atividades realizadas em sala.

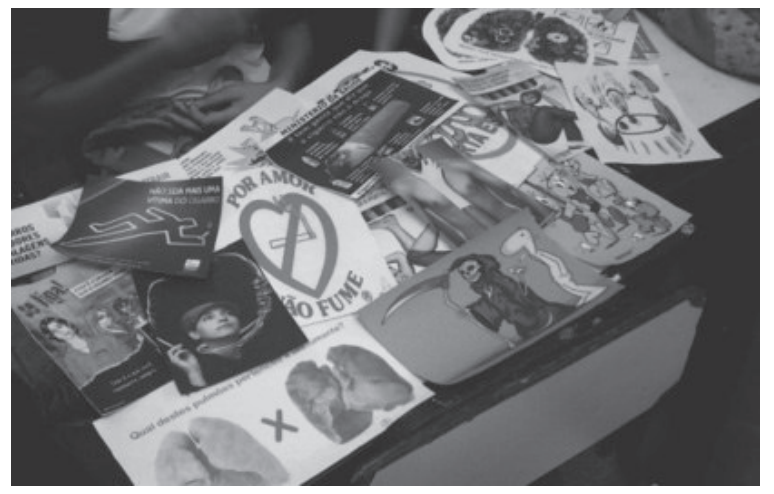

Fotografia 1a - imagens escolhidas pelos alunos

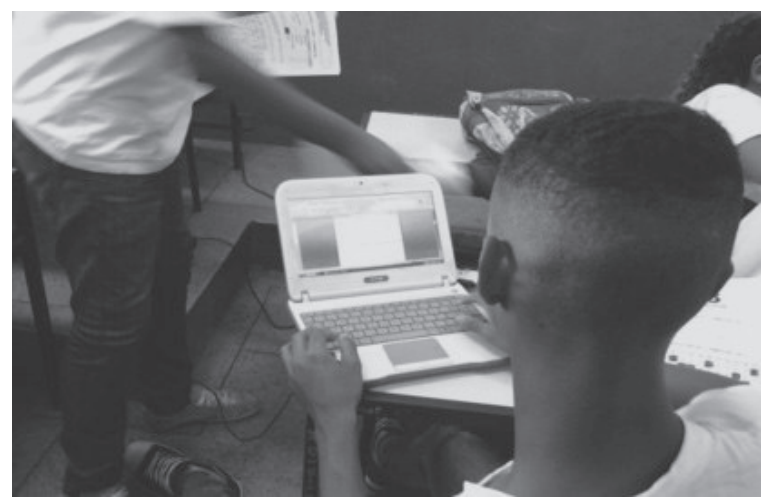

Fotografia $1 b$ - opinião no editor de texto

Fonte - Arquivo pessoal, 2013.

Como mais uma estratégia para usar o computador na sala para reforçar novamente a reflexão sobre os efeitos do tabagismo na adolescência e como uma alusão à Lei Municipal da cidade do Rio de Janeiro, n 5577, de 03 de maio de 2013, que instituiu o dia 11 de outubro como Dia de Combate ao Tabagismo da Criança e do Adolescente (RIO DE JANEIRO, 2013, p. 3), a atividade do quarto encontro foi a confecção das opiniões dos 
alunos no computador: cada aluno, então, utilizando um netbook disponível na sala de aula, escreveu num programa de texto sua opinião a respeito do tabagismo, escolhendo, também, o leiaute - características como o tipo, o tamanho e a cor da fonte e do balão onde escreveram sua opinião. A única instrução era a de que a opinião coubesse numa folha A4, com orientação de paisagem (Figura 1 - fotografia $1 b$ ).

Essa solicitação foi atendida pelos alunos e, assim, houve material suficiente para a atividade seguinte, que foi a elaboração de mais um cartaz que teve como tema: "Por que não se deve fumar?”. Alguns alunos, voluntariamente, dispuseram-se a ajudar na elaboração do mesmo e parte do material preparado pelas turmas foi exposto no saguão da escola (Figura 2 - fotografias 2 a e $2 b$ ).

\section{Figura 2 - Elaboração do cartaz Por que não se deve fumar?}

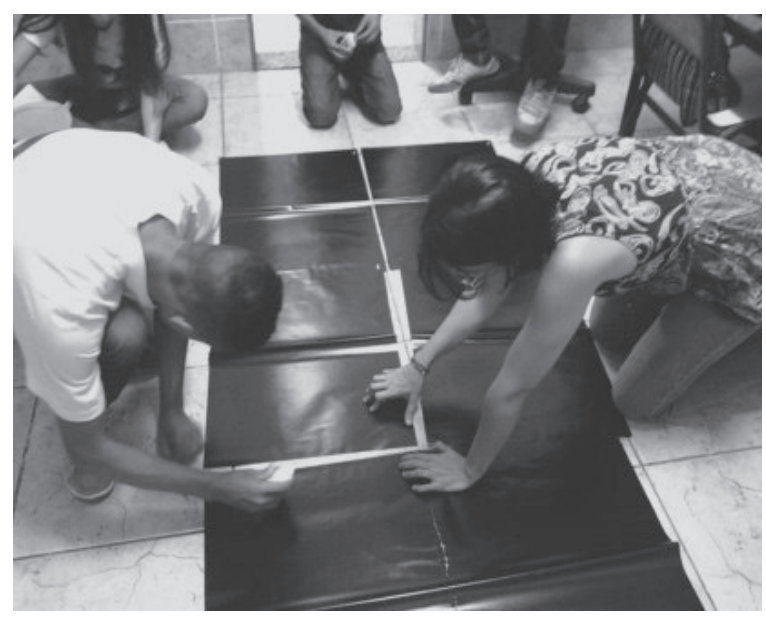

Fotografia 2a - Elaboração do cartaz

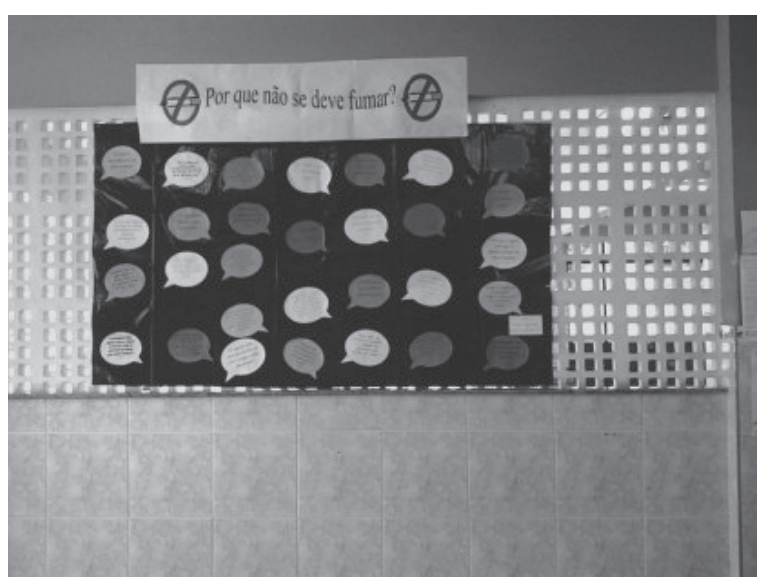

Fotografia $2 b$ - Cartaz exposto.

Fonte - Arquivo pessoal, 2013.

A professora fez uma prévia análise das opiniões dos alunos e, no quinto encontro, mostrou à turma os resultados da última pergunta do questionário, por meio de uma nuvem de texto, também conhecida como nuvem de palavras. Como explica Lunardi e Castro (2008, p. 5),

[...] as nuvens de texto são compostas, basicamente, como seu nome indica, por textos e tem como objetivo principal proporcionar uma compreensão rápida, um resumo do conteúdo determinado texto ou conjunto de textos, a partir de suas palavras mais frequentes. 
Aproveitando o ensejo da curiosidade que foi despertada, os alunos encaminharamse novamente para a Sala de Informática, onde tiveram a oportunidade de, concomitantemente às explicações da professora, fazer suas próprias nuvens de palavras, utilizando o programa Wordle ${ }^{\mathrm{TM}}$, sobre o tema Tabagismo, com frases que eles mesmos criaram e/ ou obtinham como respostas de seus colegas para a pergunta: "Qual é a sua opinião a respeito do cigarro?” (Figura 3)

Figura 3 - Exemplos de nuvem de palavras.

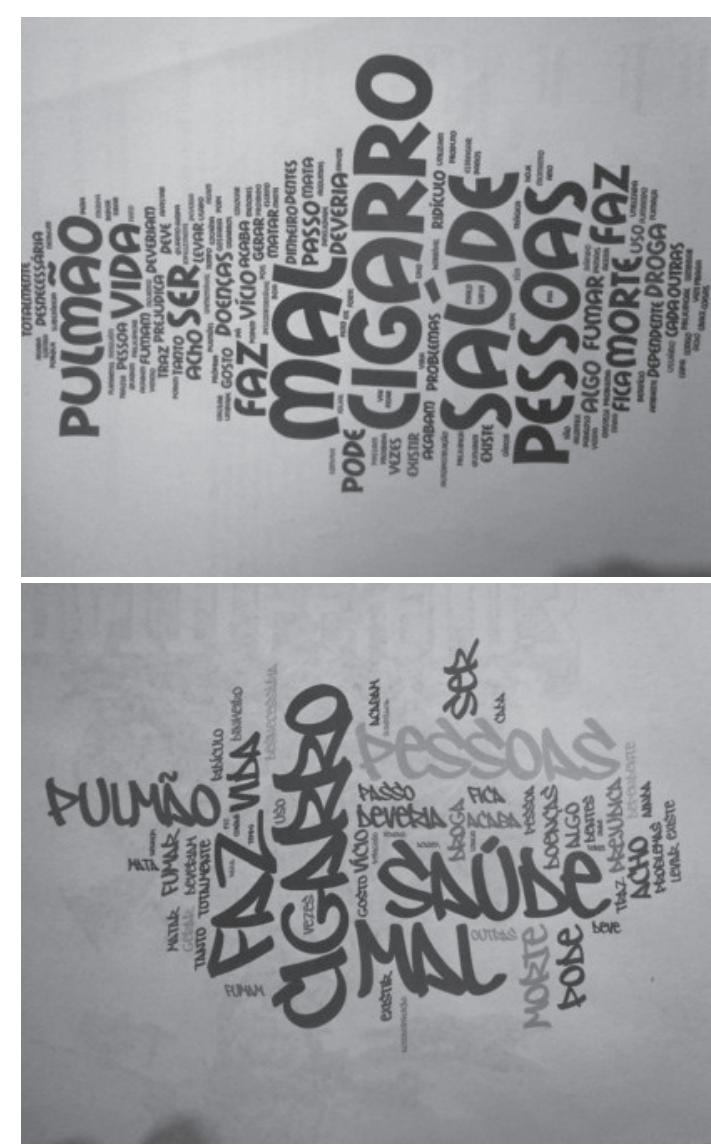

Fonte - Arquivo pessoal, 2013.

Como atividade finalizadora, no sexto encontro, os alunos receberam uma cartilha produzida por uma organização não governamental que trata das drogas lícitas e ilícitas, numa linguagem adequada ao público adolescente e jovem. Os alunos puderam ler e, novamente, opinar sobre o tema, inclusive trocando informações e experiências de vivência com cigarro, álcool e algumas drogas ilícitas.

\section{Breve análise do questionário aplicado}

Foram aplicados 48 questionários e, quanto ao perfil dos alunos, $78 \%$ dos alunos têm idade entre 14 e 15 anos e 98\% não fumam. Podemos inferir que reportagens esclarecedoras sobre os malefícios do tabagismo, a proibição à glamourização do cigarro na mídia aliadas às políticas de educação para esclarecimento possam ter ajudado os adolescentes a optarem por não fumar. Ainda assim, 95\% desses alunos conhecem outros adolescentes que, mesmo com toda campanha educativa, optam por fumar cigarro de tabaco.

Entre os alunos, 77\% declaram que têm um familiar que fuma - pai, mãe e tios. Tal fato pode ser explicado por fatores históricos: no século passado, principalmente entre 
os anos de 1960 e 1970, havia uma influência da indústria do cigarro na mídia, como nas produções de filmes e comerciais de televisão. Desta feita, crianças e adolescentes desta época cresceram com uma imagem positiva de prestígio e de status sobre o tabagismo, conferindo o que poderia explicar certa normalidade de se fumar cigarro de tabaco nesta época. Assim, essas crianças e esses adolescentes desse passado podem ter sido influenciados a experimentar, tornando-se os fumantes que atualmente são pais e mães dos nossos alunos em idade escolar.

No Brasil, a limitação de horários de propagandas de cigarro ocorreu a partir de 1996, por meio da Lei no 9.294, de quinze de julho de 1996 (BRASIL, 1996), o que diminuiu consideravelmente a exposição da criança e do adolescente a uma imagem positiva do hábito de fumar.

Esses dois resultados apurados - o tabagismo dos pais e o tabagismo de amigos - são registrados na literatura acadêmica como fatores de risco associados significativamente ao tabagismo na adolescência (BARBOSA; CARLINI-COLTRIN; SILVA FILHO, 1989, p. 408; IVANOVIC; CASTRO; IVANOVIC, 1997, p. 37).

A última pergunta: “Qual a sua opinião a respeito do uso do cigarro?” levou a respostas em que, por análise das nuvens de texto, as palavras cigarro, mal, saúde, pessoas foram as mais citadas, seguidas de pulmão, morte e vida. A partir desses dados, podemos considerar que os alunos têm associado o cigarro a prejuízos para a saúde.

\section{Análise dos resultados do relato de experiência}

Admitindo-se na postura de professora pesquisadora da própria prática pedagógica, “[...] no sentido de saber usar e produzir pesquisa para alimentar a atualização permanente de seu exercício profissional" (DEMO, 2010, p. 77), os resultados e as discussões deste relato foram analisados sobre o arcabouço teórico de Vygotsky, "[...] na medida em que vê o aprendizado como um processo profundamente social, enfatiza o diálogo e as diversas funções da linguagem na instrução e no desenvolvimento cognitivo" (VYGOTSKY, 2007, p. 164).

A interação social do projeto ocorreu por meio de atividades realizadas em grupo, permitindo a troca de informações entre os alunos sobre o assunto, promovendo o desenvolvimento do espírito crítico e também a oportunidade de ouvir o outro.

No entanto, as atividades em grupo, principalmente nos dois primeiros encontros, mostraram-se difíceis de acontecer, pois os alunos queriam impor suas próprias opiniões, o que significava falar mais alto que o outro, ofender e não ouvir a opinião do colega. Assim, foram necessárias certas regras de postura na hora da dinâmica entre os grupos: "Uma pessoa fala de cada vez", "Não gritar com seu colega" e "É proibido ofender". À medida que o projeto se desenvolvia, visivelmente, os alunos começaram a se comportar socialmente melhor, compreendendo o fato de terem o tempo de falar e o tempo para ouvir, e acatando as decisões que eram tomadas de forma coletiva, como a escolha da figura que representaria o tabagismo.

Como a apropriação do conteúdo ocorre por intermédio do contato social, pois Vygotsky considera o ser humano eminentemente social (SMOLKA; GÓES, 1993, p. 153), os alunos compartilharam experiências e informações sobre o cigarro, descobrindo informações que até então não sabiam. Por exemplo, os alunos demonstraram surpresa e até asco ao conhecer outras substâncias que compõem o cigarro de tabaco, como a acetona, a naftalina e o formol, que são substâncias com as funções respectivas de removedor de esmalte, mata-baratas e conservante de cadáver. A fala de um deles pode resumir o sentimento do grupo: "Pô, professora, cigarro só tem porcaria!"

A distribuição da cartilha, sua leitura e o posterior compartilhamento de opiniões também revelou que alguns alunos desconheciam o fato de algumas substâncias com que 
eles lidam no dia a dia serem consideradas drogas, como xaropes, moderadores de apetite e até mesmo a cafeína. Também desconheciam a existência de algumas substâncias como solvente, anfetamínicos e ansiolíticos. Como tal situação estava prevista, a professora preparou-se, antecipadamente, pesquisando sobre os termos para os esclarecimentos devidos.

A atitude descrita acima confirma a necessidade de, no planejamento do docente, incluir possibilidades que possam ocorrer durante a dinâmica da aula e que são passíveis de serem previstas. Essa necessidade de aperfeiçoamento do conhecimento permite que a professora também aprenda e compartilhe o que sabe com seus alunos.

O uso do computador foi motivador e ao mesmo tempo um desafio para as atividades. Motivador porque os alunos demonstraram empolgação para usar a máquina nas diferentes situações propostas, seja utilizando a internet para procurar figuras, seja na digitação da sua opinião no editor de texto e, também, na criação da nuvem de palavras.

Uma vertente do desafio ficou por conta de que foi necessário orientar os grupos quanto ao uso compartilhado - alguns alunos demonstraram dificuldade de ceder o computador para o colega. A outra vertente foi que alguns alunos apresentaram apenas interesse em utilizar o computador se este permitisse o acesso às redes sociais que costumam acessar, fato pontuado pela autora ao trabalhar em outra turma de alunos adolescentes (GOMES, 2013, p. 112).

Nessa situação, o papel da professora tornou-se fundamental ao ajudá-los a perceber outras possibilidades do uso do computador. Esta postura corrobora com Bizzo ao comentar que os computadores são incapazes de "[...] substituir alunos e professores em suas tarefas básicas e essenciais, sendo apenas ferramenta à disposição da escola” (BIZZO, 2009, p. 104).

Ainda em meio aos desafios apresentados, é reconhecido que o uso de informática como elemento motivador foi um subsídio fundamental para que os alunos continuassem motivados a conversar sobre o tabagismo na adolescência e emitir suas próprias opiniões.

\section{Considerações finais}

Mesmo com o aparente caos no início do projeto, é preciso propor aos alunos atitudes para que saiam desta zona de imposição de opinião, auxiliando-os a desenvolver a postura de tolerância e de respeito à opinião alheia; habilidades que podem ser desenvolvidas na escola em qualquer área do conhecimento, as quais são efetivamente importantes para o convívio na sala de aula e na sociedade.

A escola tem o privilégio de ser um espaço onde cada assunto tratado desenvolve uma relação específica com o aluno, considerando suas características intrínsecas em cada idade biopsicológica e também do grupo social no qual o aluno está inserido.

Nessa perspectiva, a abordagem de um assunto deve estar cada vez mais amplamente imbuída dessa realidade social, mesmo porque é necessário criar pontes de significação entre o conhecimento que é proposto pela escola com aquilo que o aluno vive e traz para a escola.

Para tanto, o professor não pode ignorar seu papel de mediador e criador destas pontes de significação, motivando e estimulando a atividade intelectual e social dos alunos, como apregoam Krasilchik e Marandino (2007, p. 53).

Ademais, reconhece-se o aluno como sujeito da própria aprendizagem (DELIZOICOV; ANGOTTI; PERNAMBUCO, 2007, p. 152) o que traduz por um ser humano ativo, pensante, com ideias a serem discutidas em sala de aula que fomentam também a significação do conhecimento científico que lhe é apresentado.

Estratégias diversificadas são necessárias, para que escola, família e Estado atuem juntos, esclarecendo aos adolescentes os riscos do tabagismo, protegendo-os e também oferecendo opções de escolha, para que eles se sintam seguros, para recusarem a primeira tragada. 
Apesar de o tabagismo ser um tema aparentemente conhecido pelos alunos, o uso do computador foi perceptivelmente o motivador, para que eles se sentissem estimulados a participar. $\mathrm{O}$ assunto intermediado pela tecnologia levou a um engajamento cada vez maior em cada etapa do projeto.

\section{Referências}

BARBOSA, Maria Tereza Serrano. CARLINI-COTRIM, Beatriz. SILVA-FILHO, Armando Ramos. O uso de tabaco por estudantes de primeiro e segundo graus em dez capitais brasileiras: possíveis contribuições da estatística multivariada para compreensão do fenômeno. Rev. Saúde Pública [online], v.23, n.5, p. 401-409, 1989. Disponível em: http://www.scielo.br/pdf/rsp/v23n5/07.pdf . Acesso em 21 nov. 2013.

BIZZO, Nélio. Ciências: fácil ou difícil? São Paulo: Biruta, 2009.

BORBA, Marcelo de Carvalho; PENTEADO, Miriam Godoy. Informática e Educação Matemática. Belo Horizonte: Autêntica, 2001.

BRASIL, 1996. Lei no 9.294, de 15 de julho de 1996. Dispõe sobre as restrições ao uso e à propaganda de produtos fumígeros, bebidas alcoólicas, medicamentos, terapias e defensivos agrícolas, nos termos do $\$ 4^{\circ}$ do art. 220 da Constituição Federal. Disponível em: http://www.planalto.gov. br/ccivil_03/leis/19294.htm. Acesso em: 21 nov. 2013.

2002. Jovem/Mulher e Tabaco. Disponível em: http://www.inca.gov.br/tabagismo/frameset. asp?item=jovem\&link=namira.htm. Acesso em: 02 nov. 2013.

, 2006. Lei $n^{\circ} 11343$, de 23 de agosto de 2006. Regulamento Institui o Sistema Nacional de Políticas Públicas sobre Drogas - Sisnad; prescreve medidas para prevenção do uso indevido, atenção e reinserção social de usuários e dependentes de drogas; estabelece normas para repressão à produção não autorizada e ao tráfico ilícito de drogas; define crimes e dá outras providências. Disponível em: http://www.planalto.gov.br/ccivil_03/_Ato2004-2006/2006/Lei/L11343.htm. Acesso em: 21 nov. 2013.

2008. F10-F19 Transtornos mentais e comportamentais devidos ao uso de substância psicoativa. Disponível em: http://www.datasus.gov.br/cid10/V2008/WebHelp/f10_f19.htm. Acesso em: 16 nov. 2013.

CEBRID - Centro Brasileiro de Informações sobre Drogas Psicotrópicas. V Levantamento Nacional sobre o Consumo de Drogas Psicotrópicas entre Estudantes do Ensino Fundamental e Médio da Rede Pública de Ensino nas 27 capitais brasileiras - 2004. Disponível em: http://200.144.91.102/cebridweb/ conteudo.aspx?cd=644. Acesso em: 16 nov. 2013.

DAVIM, Rejane Maria Barbosa; GERMANO, Raimunda Medeiros; MENEZES, Rejane Millions Viana; CARLOS, Djailson José Delgado. Adolescente/adolescência: revisão teórica sobre uma fase crítica da vida. Rev. Rene. Fortaleza, v. 10, n. 2, p. 131-140, abr./jun. 2009.

DELIZOICOV, Demétrio; ANGOTTI, José André; PERNAMBUCO, Marta Maria. Ensino de Ciências: Fundamentos e Métodos. 2a ed. São Paulo: Cortez, 2007.

DEMO, Pedro. Educação e alfabetização científica. Campinas: Papirus, 2010.

FARINA, Marianne; PEREIRA, Fabrícia da Silva; ARGIMON, Irani de Lima. Tabagismo na adolescência. Trabalho apresentado no IX Salão de Iniciação Científica PUCRS, 2008.

GOMES, Luciana Maria de Jesus Baptista de. Ensinando as leis de Newton por meio de recursos midiáticos e de recursos experimentais. Rev. ARETÉ, v. 6, n. 10, p.119-128, jan./jun. 2013. Disponível em: http://www.revistas.uea.edu.br/download/revistas/arete/vol.6/arete_v6_n10-2013-p.107-115. pdf. Acesso em: 21 nov. 2013.

IVANOVIC, Daniza; CASTRO, Carmen; IVANOVIC, Rodolfo. Factores que inciden en el habito de fumar de escolares de educación basica y media del Chile. Rev. Saúde Pública [online], v.31, n.1, p. 30-43, 1997. Disponível em: http://www.scielo.br/pdf/rsp/v31n1/2219.pdf. Acesso em: 21 nov. 2013.

KRASILCHIK, Myriam; MARANDINO, Martha. Ensino de ciências e cidadania. 2. ed. São Paulo: Moderna, 2007. 
LUNARDI, Márcia Severo e CASTRO, José Muanis Fernandes de. Visualização dos resultados do Yahoo em nuvens de texto: uma aplicação construída a partir de web services. Apresentado no $2^{\circ}$ EBAI - Encontro Brasileiro de Arquitetura de Informação - 2008. Disponível em: http://www. congressoebai.org/wp-content/uploads/ebai08/4.pdf. Acesso em: 15 nov. 2013.

MILARÉ, Tathiane; RICHETTI, Graziela Piccoli. Alfabetização Científica no Ensino de Química: um olhar sobre os temas sociais. XIV Encontro Nacional de Ensino de Química (XIV ENEQ) UFPR, 21 a 24 de julho de 2008. Curitiba/PR., 2008.

RIO DE JANEIRO: Secretaria Municipal de Educação, 2013. Rio de Janeiro, 2013. Lei Municipal $n^{\circ}$ 5577, de 03 de maio de 2013. Institui o dia 11 de outubro como Dia de Combate ao Tabagismo da Criança e do Adolescente. Publicada no Diário Oficial do Município do Rio de Janeiro de 06 de maio de 2013.

SMOLKA, Ana Luiza Bustamante; GÓES, Maria Cecília Rafael de. A linguagem e o outro no espaço escolar: Vygotsky e a construção do conhecimento. Campinas: Papirus, 1993.

VYGOTSKY, Lev Semenovitch. A formação social da mente: o desenvolvimento dos processos psicológicos superiores. Michael Cole et al (Orgs.). Tradução de José Cipollo Neto, Luís Silveira Menna Barreto e Solange Castro Afeche. 7. ed. São Paulo: Martins Fontes, 2007.

WORLD HEALTH ORGANIZATION. WHO report on the global tobacco epidemic, 2013: Enforcing bans on tobacco advertising, promotion and sponsorship. Disponível em: http://www.who.int/ tobacco/global_report/2013/summary.pdf. Acesso em: 16 nov. 2013.

ZABALA, Antoni. A prática educativa: como ensinar. Tradução de Ernani F. da Rosa. Porto Alegre: Artmed, 1998.

\section{Apêndice 1: Questionário inicial}

1. Idade:

2. Sexo: ( ) Feminino ( ) Masculino

3. Você fuma cigarro de tabaco?
( ) Sim
( ) Não

4. Você conhece ou é amigo de alguém da sua idade que fuma?
( ) Sim
( ) Não

5. Na sua família, alguém fuma?
( ) Sim
( ) Não

6. Qual é a sua opinião a respeito do cigarro? 